\title{
SPATIOLTEMPORAL MODELING THE IMPACT OF SURFACE CHARACTERISTICS VARIATIONS ON LAND SURFACE TEMPERATURE VARIATIONS: A CASE STUDY OF SAMALGHAN VALLY
}

\author{
M. K. Firozjaei ${ }^{1}$, M. Makki ${ }^{2}$, J. Lentschke ${ }^{2}$, M. Kiavarz ${ }^{1 *}$, S. K. Alavipanah ${ }^{1}$ \\ ${ }^{1}$ Dept. of Remote Sensing and GIS, Geography Faculty, University of Tehran, Tehran, Iran - (Mohammad.karimi.f, kiavarzmajid, \\ salavipa)@ut.ac.ir \\ ${ }^{2}$ Department of Geography, Humboldt-Universität zu Berlin - makki@hu-berlin.de, jan.lentschke@cms.hu-berlin.de
}

\author{
Commission VI, WG VI/4
}

KEY WORDS: LST variation, surface parameters, PCA, PLSR, Samalghan Valley.

\begin{abstract}
:
Spatiotemporal mapping and modeling of Land Surface Temperature (LST) variations and characterization of parameters affecting these variations are of great importance in various environmental studies. The aim of this study is a spatiotemporal modeling the impact of surface characteristics variations on LST variations for the studied area in Samalghan Valley. For this purpose, a set of satellite imagery and meteorological data measured at the synoptic station during 1988-2018, were used. First, single-channel algorithm, Tasseled Cap Transformation (TCT) and Biophysical Composition Index (BCI) were employed to estimate LST and surface biophysical parameters including brightness, greenness and wetness and BCI. Also, spatial modeling was used to modeling of terrain parameters including slope, aspect and local incident angle based on DEM. Finally, the principal component analysis (PCA) and the Partial Least Squares Regression (PLSR) were used to modeling and investigate the impact of surface characteristics variations on LST variations. The results indicated that surface characteristics vary significantly for case study in spatial and temporal dimensions. The correlation coefficient between the PC1 of LST and PC1s of brightness, greenness, wetness, BCI, DEM, and solar local incident angle were $0.65,-0.67,-0.56,0.72,-0.43$ and 0.53 , respectively. Furthermore, the coefficient coefficient and RMSE between the observed LST variation and modelled LST variation based on PC1s of brightness, greenness, wetness, BCI, DEM, and local incident angle were 0.83 and 0.14 , respectively. The results of study indicated the LST variation is a function of s terrain and surface biophysical parameters variations.
\end{abstract}

\section{INTRODUCTION}

Land surface temperature (LST) is considered as controller parameter of surface energy exchanges top of land surface (Anderson et al. 2008; Prata et al. 1995; Weng et al. 2019). The role of land surface temperature (LST) in the energy exchanges between land surface and atmosphere is significant. Currently, using from satellite-based thermal infrared (TIR) remote sensing data in physical and quantitative models a popular method to obtain LST maps at different spatiotemporal scales (Zhao et al. 2019).

LST is extremely changeable and affected by various parameters in both spatial and temporal dimensions (Guo et al. 2015). These parameters include temporal characteristics, geographic coordinates, topographic factors, thermal surface properties, biophysical parameters, soil texture, meteorological parameters and sub-surface features (geothermal, hydrothermal and volcanic areas) (Weng et al. 2019).

Considering of LST variations is among the most effective factors on the surface energy balance components (Weng et al. 2019), surface soil moisture (Jiang and Weng 2017), climate change (Weng 2009), drought (Son et al. 2012), evapotranspiration (Jiang and Weng 2017), global warming (Xie et al. 2010), Urban Heat Island Intensity (UHII) (Firozjaei et al. 2018; Weng et al. 2018), energy consumption (Giridharan and Emmanuel 2018), thermal comfort (Van Hove et al. 2015). Therefore, study of LST variations and the parameters affecting these changes is important (Karimi Firozjaei et al. 2018; Weng et al. 2019).

In many previous studies, the impact of land use and land cover changes on LST were investigated (Jiang and
Tian 2010; Xiao and Weng 2007). In some studies the impact of surface biophysical parameters on LST using of fundamental surface descriptors such as Normalized Difference Vegetation Index (NDVI) (Weng et al. 2004), Normalized Difference Built up Index (NDBI) (Li et al. 2009) and surface topography (Zhao et al. 2019) were investigated. Zhan et al. (2013) provided an overview of multiple indices, which used to model the LST spatial changes (Zhan et al. 2013). Hutengs and Vohland (2016) studied about modeling of LST with considering of digital elevation data, surface reflectance, and land cover maps (Hutengs and Vohland 2016). Sismanidis et al. (2017) selected NDVI data, DEM, albedo and land surface emissivity data as the effective factors for modeling of LST (Sismanidis et al. 2016). He et al. (2018) provided a systematic analysis about the impact of the environmental parameter which effect on LST and presented the effective factors that influence LST (He et al. 2018).

In most studies, to determine the impact of surface biophysical parameters on the LST, regression techniques were employed (Sattari et al. 2018; Yang et al. 2017). Also, in these studies, the relationship between surface characteristics and LST variations were investigated in the spatial dimension (Sattari et al. 2018; Yang et al. 2017). One of the drawbacks of previous studies is the lack of examining the impact of surface characteristics variations on LST in both spatial and temporal dimensions under an integrated model.

The aim of this study is to introduce a method to model the impact of surface characteristics variations on LST variations for the studied area in Samalghan Valley. For this purpose, two basic steps were taken: (1) Using of principal component analysis (PCA) to determine the LST and surface characteristics variations in the temporal dimension; (2) using of Partial Least

\footnotetext{
* Corresponding author
} 
Squares Regression (PLSR) to investigate the impact of surface characteristics variations on LST variations. Surface biophysical characteristics including brightness, greenness, wetness and Biophysical Composition Index (BCI) and terrain parameters including DEM and local incident angle were considered as main effective factors on LST in this study.

\section{PROPOSED METHOD}

\subsection{Studied area}

The study area included Samalghan Valley and its suburbs with an approximate area of $2471 \mathrm{Km} 2$. Geographically, case study locates from $56^{\circ} 36^{\prime} 29^{\prime \prime}$ and $57^{\circ} 14^{\prime} 36^{\prime \prime}$ E longitude and from $37^{\circ} 21^{\prime} 37^{\prime \prime}$ and $37^{\circ} 45^{\prime} 21^{\prime \prime} \mathrm{N}$ latitude. The region is distanced $262 \mathrm{~km}$ from the Caspian Sea, $90 \mathrm{~km}$ from the Hyrcanian forests, and $33 \mathrm{~km}$ from the Bojnord (capital city of North Khorasan province, Iran). The average height of this city is about 1111 meters above sea level. The climatic conditions of the studied area are moderate and dry. The location of the study area is shown in Figure 1.

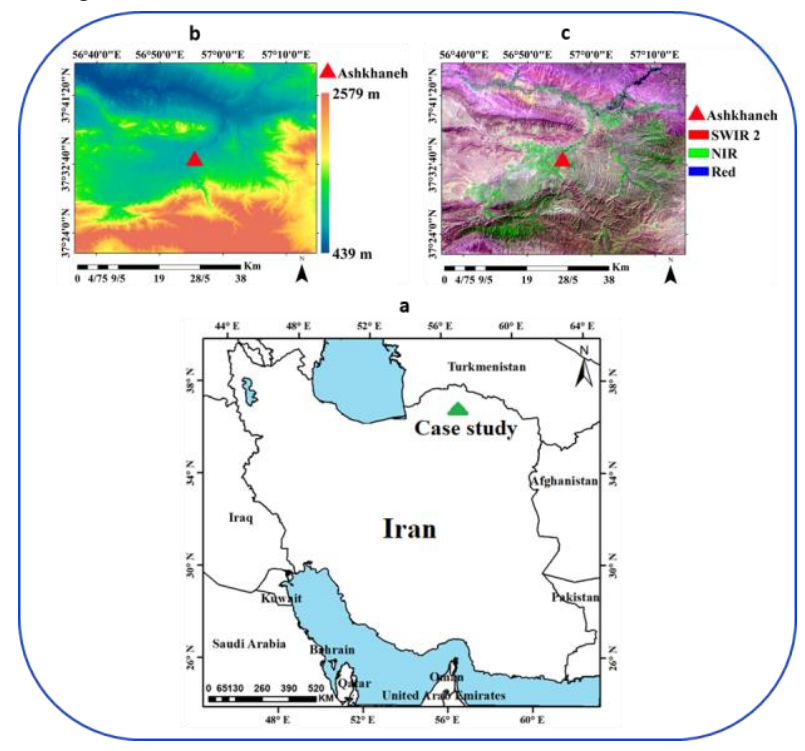

Figure 1. The study area

\subsection{Data}

Landsat imagery of the studied area for 20/07/1988, 15/07/1992, 13/07/1997, 25/06/2002, 27/07/2008, 12/07/2014 and $07 / 07 / 2018$ were used to derive surface biophysical characteristics. These images were georeferenced in UTM coordinate system and located in zone $40 \mathrm{~N}$. The downloaded data from the USGS included the highest quality Level-1 Precision Terrain (L1TP) data which were considered suitable for timeseries analysis. The geo-registration was consistent and the root mean square error (RMSE) less than 12 meters $(\leq 0.5$ pixel) (Weng et al. 2019). The Moderate Resolution Imaging Spectroradiometer (MODIS) Atmospheric Profiles products (MOD07), were exploited to complete the input parameters, and estimation of LST maps from Landsat images. Also, The ASTER Digital Elevation Model (GDEM) was used to derive various topographical parameters including elevation, slope, aspect and the solar local incidence angle. The air temperature and relative humidity data for the days which related to the images date for free by the meteorological organization of Northern Khorassan ("www.nkhmet.ir") were used.

\subsection{Method}

The methodologies were applied to achieve the current study objectives are presented in Figure 2. In the first step, the preprocessing of utilized satellite images has been done including atmospheric corrections, radiometric corrections and subset of the studied area. In the second step, from spatial modeling, single-channel algorithm (Jiménez-Muñoz et al. 2014; Sobrino et al. 2004), Tasseled Cap Transformation (TCT) (Baig et al. 2014) and BCI (Deng and Wu 2012) based on reflective and thermal bands of Landsat imagery, GDEM, MODIS product and meteorological data the LST, brightness, greenness, wetness, $\mathrm{BCI}$, and local incident angle were extracted for the period from 1988 to 2018. In the next step, the PCA (Jolliffe 2011) was employed to determine the degree of variation of the LST and surface characteristics in the temporal dimension at pixel scale. The PCA is one of the techniques for determining variations of environmental parameters in the temporal dimension (Dalal et al. 2010). The variations of environmental parameters in the temporal dimension can be examined on a pixel scale using PCA (Vázquez-Jiménez et al. 2017). To model the variations of each particular parameter over a given time interval, the PCA model applied to its specific values over a time scale at a scale of each pixel (de Almeida et al. 2015; Gaitani et al. 2017; Hirosawa et al. 1996; Wang et al. 2010). PC1 output contains negative and positive values. The higher and more positive value of a pixel in PC1 indicates that the values of this pixel have been large and unchanged over time. But, the lower and more negative value of a pixel in PC1 indicates that the values of that pixel have been low and unchanged over time. The value of PC1 which closer to zero indicates that changes in the values of pixel have been high over time. Finally, the PLSR (Farifteh et al. 2007) was used to investigate the impact of surface characteristics variations on LST variations.

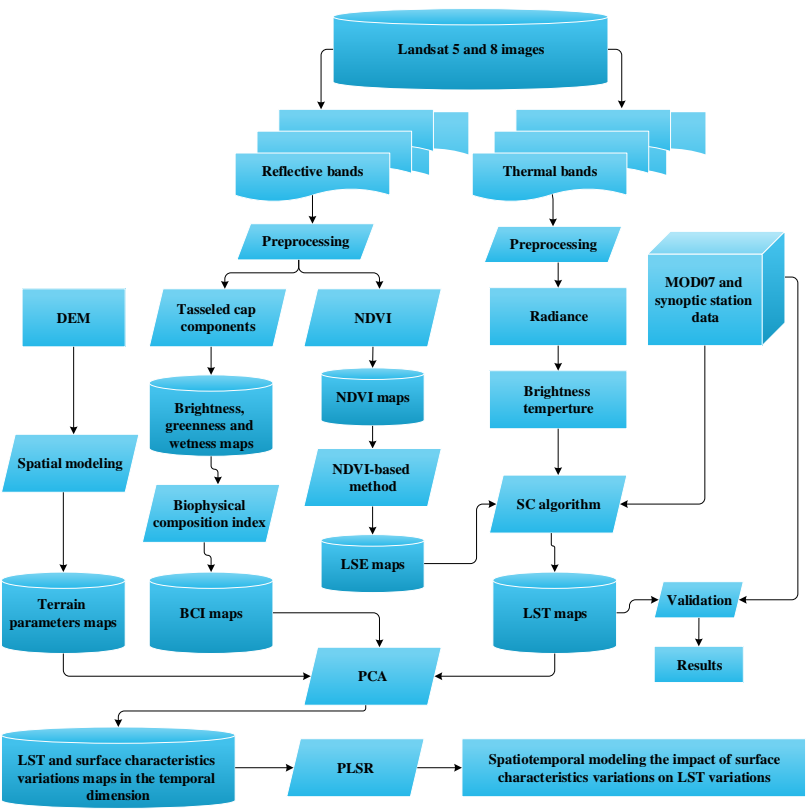

Figure 2. The analytical procedures of the study

\section{RESULTS}

The results indicated that the mean LST for the studied area is changing over the study period (Figure 3). 


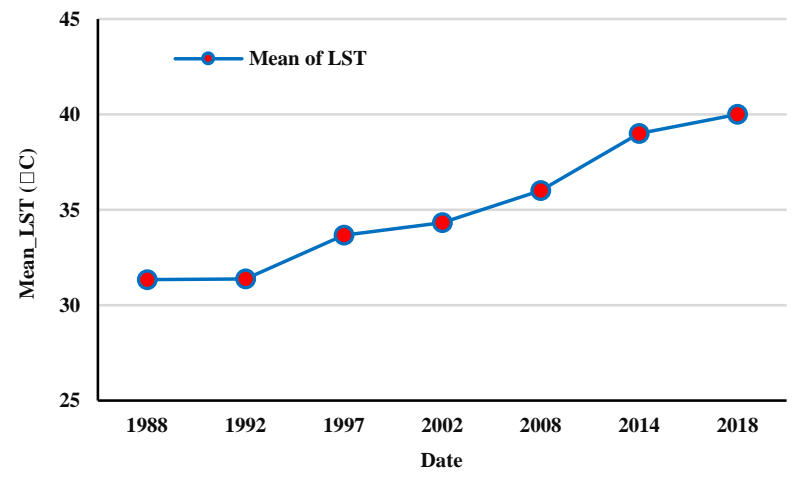

Figure 3. The mean LST of the studied region for 1988 to 2018 $\left({ }^{\circ} \mathrm{C}\right)$.

Previous studies have shown that the LST response is specified by surface characteristics such as the surface moisture, vegetation cover and impervious surface and topographical parameters (Deng and Wu 2013; Xunqiang et al. 2011; Yang et al. 2017). Surface biophysical and topographical parameters are the most important factors influencing on spatial-temporal variations of LST is variations between the other factors.

The PCA was applied for the deeper analysis of the LST variations and each of the surface characteristics at the pixel scale from 1988 to 2018 (Figure 4). The PC1 output contains negative and positive values. The higher and more positive value of a pixel in PC1 indicates that the values of this pixel have been large and unchanged over time. But, the lower and more negative value of a pixel in PC1 indicates that the values of that pixel have been low and unchanged over time. The value of PC1 which closer to zero indicates that changes in the values of pixel have been high over time (Figure 4 ).

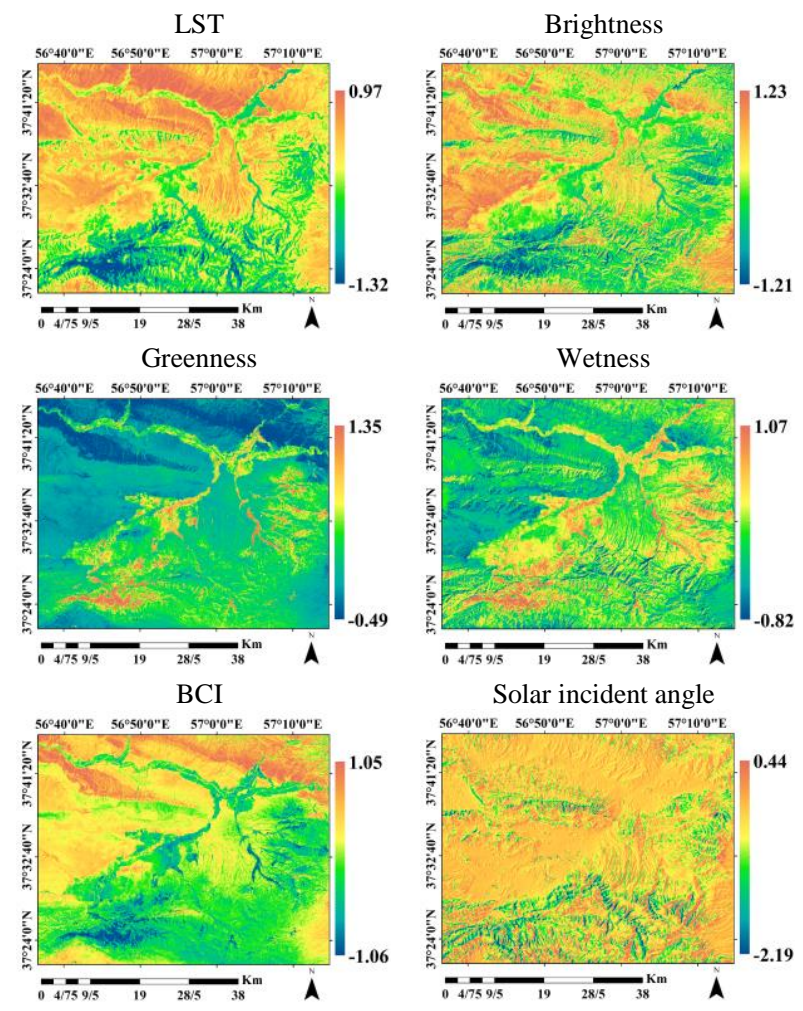

Figure 4. The PC1 maps of LST and various surface characteristics.

The relationship between the PC1 of LST and the PC1 of each surface characteristics were investigated using PLSR (Table 1).
Based on regional approach, among the various surface characteristics, BCI variations showed the highest impact on the LST variations. In general, for study area, the effect of surface biophysical characteristics on LST variation was greater than the effect of topographical parameters (Table 1). The value of LST decreases with increasing surface brightness and reduced vegetation and moisture of surface, and vice versa (Choudhury et al. 2018; Sattari et al. 2018). A negative relationship between vegetation and moisture indices and LST is due to the effect of surface thermal inertia and evapotranspiration (Zhao et al. 2019). On the study of spatial and temporal LST variations in the case study, due to extensive areas and heterogeneous topography, the impacts of topographic effect such as lapse rate and downward solar radiation to the surface were considered (Table 1).

\begin{tabular}{c|cccccc}
\hline $\begin{array}{c}\text { Surface } \\
\text { parameter } \\
\mathbf{s}\end{array}$ & $\begin{array}{c}\text { Solar } \\
\text { incid } \\
\text { ence } \\
\text { angle }\end{array}$ & DEM & $\begin{array}{c}\text { Green } \\
\text { ness }\end{array}$ & $\begin{array}{c}\text { Wetnes } \\
\mathrm{s}\end{array}$ & $\begin{array}{c}\text { Bright } \\
\text { ness }\end{array}$ & BCI \\
\hline $\mathbf{R}^{2}$ & 0.53 & -0.43 & -0.67 & -0.56 & 0.65 & 0.72 \\
\hline
\end{tabular}

Table 1. Relationship between the PC1 of LST and the PC1 of each surface biophysical parameters using PLSR with regional approach.

Using the multivariate PLSR, it is possible to consider the influence of several dependent parameters on an independent parameter. In this study, through the simultaneous consideration of the PC1 of the surface characteristics and the PC1 of the LST, the impact of a set of surface characteristics (BCI, Solar incidence angle, and DEM) on LST variation was investigated (Figure 5).

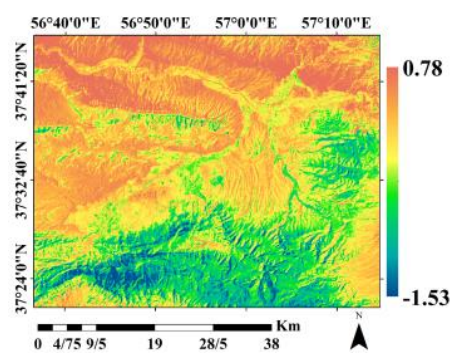

Figure 5. Modeled LST variations based on BCI, Solar incidence angle, and DEM variations using multivariate PLSR.

The results assessment of the relationship between the surface characteristics variations and the LST variations are shown in Table 2. The results assessment indicated that the LST variations can be modeled with the high precision considering the surface characteristics variations such as the BCI, Solar incidence angle, and DEM.

\begin{tabular}{c|c}
\hline Parameters & Regional approach \\
\hline R & 0.83 \\
RMSE & 0.14 \\
\hline
\end{tabular}

Table 2. Assessment of the relationship between the surface characteristics variations and the LST variations.

Simultaneous investigation of the relationship between the variations in surface characteristics and LST variations is of great importance (Karimi Firozjaei and Kiavarz 2018; Zhao et al. 2019). 


\section{CONCLUSIONS}

Variations of LST is among the most effective factors on the surface energy balance components, surface soil moisture, climate change, drought, evapotranspiration, global warming, Urban Heat Island Intensity (UHII), energy consumption, thermal comfort. Therefore, study of LST variations and parameters affecting on it is important.

In this study, two models of PCA and PLSR were used to determine the LST and surface characteristics variations in the temporal dimension at pixel scale and investigate the impact of surface characteristics variations on LST variations. The variations of LST and surface characteristics in the temporal dimension can be examined on a pixel scale using PCA. The results of study indicated the LST variations is a function of surface parameters variations. The correlation coefficient and RMSE between the modeled LST based on based on BCI, Solar incidence angle, and DEM variations using multivariate PLSR and the observed LST were 0.81 and 0.14 , respectively. Using the integrated PCA-PLSR model is useful for modeling of various environmental parameters changes and identifying the effecting factors that it.

\section{REFERENCES}

Anderson, M., Norman, J., Kustas, W., Houborg, R., Starks, P., \& Agam, N. (2008). A thermal-based remote sensing technique for routine mapping of land-surface carbon, water and energy fluxes from field to regional scales. Remote Sensing of Environment, 112, 4227-4241

Baig, M.H.A., Zhang, L., Shuai, T., \& Tong, Q. (2014). Derivation of a tasselled cap transformation based on Landsat 8 at-satellite reflectance. Remote Sensing Letters, 5, 423-431

Choudhury, D., Das, K., \& Das, A. (2018). Assessment of land use land cover changes and its impact on variations of land surface temperature in Asansol-Durgapur Development Region. The Egyptian Journal of Remote Sensing and Space Science Dalal, S., Shirodkar, P., Jagtap, T., Naik, B., \& Rao, G. (2010). Evaluation of significant sources influencing the variation of water quality of Kandla creek, Gulf of Katchchh, using PCA. Environmental Monitoring and Assessment, 163, 49-56

de Almeida, T.I.R., Penatti, N.C., Ferreira, L.G., Arantes, A.E. $\&$ do Amaral, C.H. (2015). Principal component analysis applied to a time series of MODIS images: the spatio-temporal variability of the Pantanal wetland, Brazil. Wetlands ecology and management, 23, 737-748

Deng, C., \& Wu, C. (2012). BCI: A biophysical composition index for remote sensing of urban environments. Remote Sensing of Environment, 127, 247-259

Deng, C., \& Wu, C. (2013). Examining the impacts of urban biophysical compositions on surface urban heat island: A spectral unmixing and thermal mixing approach. Remote Sensing of Environment, 131, 262-274

Farifteh, J., Van der Meer, F., Atzberger, C., \& Carranza, E. (2007). Quantitative analysis of salt-affected soil reflectance spectra: A comparison of two adaptive methods (PLSR and ANN). Remote Sensing of Environment, 110, 59-78

Firozjaei, M.K., Kiavarz, M., Alavipanah, S.K., Lakes, T., \& Qureshi, S. (2018). Monitoring and forecasting heat island intensity through multi-temporal image analysis and cellular automata-Markov chain modelling: A case of Babol city, Iran. Ecological Indicators, 91, 155-170

Gaitani, N., Burud, I., Thiis, T., \& Santamouris, M. (2017). Highresolution spectral mapping of urban thermal properties with unmanned aerial vehicles. Building and Environment, 121, 215224
Giridharan, R., \& Emmanuel, R. (2018). The impact of urban compactness, comfort strategies and energy consumption on tropical urban heat island intensity: a review. Sustainable cities and society, 40, 677-687

Guo, G., Wu, Z., Xiao, R., Chen, Y., Liu, X., \& Zhang, X. (2015). Impacts of urban biophysical composition on land surface temperature in urban heat island clusters. Landscape and Urban Planning, 135, 1-10

He, J., Zhao, W., Li, A., Wen, F., \& Yu, D. (2018). The impact of the terrain effect on land surface temperature variation based on Landsat- 8 observations in mountainous areas. International Journal of Remote Sensing, 1-20

Hirosawa, Y., Marsh, S.E., \& Kliman, D.H. (1996). Application of standardized principal component analysis to land-cover characterization using multitemporal AVHRR data. Remote sensing of environment, 58, 267-281

Hutengs, C., \& Vohland, M. (2016). Downscaling land surface temperatures at regional scales with random forest regression. Remote Sensing of Environment, 178, 127-141

Jiang, J., \& Tian, G. (2010). Analysis of the impact of land use/land cover change on land surface temperature with remote sensing. Procedia environmental sciences, 2, 571-575

Jiang, Y., \& Weng, Q. (2017). Estimation of hourly and daily evapotranspiration and soil moisture using downscaled LST over various urban surfaces. GIScience \& remote sensing, 54, 95-117 Jiménez-Muñoz, J.C., Sobrino, J.A., Skoković, D., Mattar, C., \& Cristóbal, J. (2014). Land surface temperature retrieval methods from Landsat-8 thermal infrared sensor data. Ieee Geoscience and Remote Sensing Letters, 11, 1840-1843

Jolliffe, I. (2011). Principal component analysis. Springer

Karimi Firozjaei, M., \& Kiavarz, M. (2018). Investigating the relationship between heat island intensity and biophysical characteristics differences between built-up and non-built-up regions (Case Study: Cities in East Mazandaran). Journal of Geospatial Information Technology, 6, 165-189

Karimi Firozjaei, M., Kiavarz Mogaddam, M., Alavipanah, S., \& Hamzeh, S. (2018). Normalizing Satellite Images-Derived Land Surface Temperature Relative to Environmental Parameters Based on the Soil and Vegetation Energy Balance Equations. Journal of Geomatics Science and Technology, 7, 213-232

Li, H., Liu, Q.-h., \& Zou, J. (2009). Relationships of LST to NDBI and NDVI in Changsha-Zhuzhou-Xiangtan area based on MODIS data. Scientia Geographica Sinica, 2, 018

Prata, A., Caselles, V., Coll, C., Sobrino, J., \& Ottle, C. (1995). Thermal remote sensing of land surface temperature from satellites: Current status and future prospects. Remote Sensing Reviews, 12, 175-224

Sattari, F., Hashim, M., \& Pour, A.B. (2018). Thermal sharpening of land surface temperature maps based on the impervious surface index with the TsHARP method to ASTER satellite data: A case study from the metropolitan Kuala Lumpur, Malaysia. Measurement, 125, 262-278

Sismanidis, P., Keramitsoglou, I., Bechtel, B., \& Kiranoudis, C. (2016). Improving the downscaling of diurnal land surface temperatures using the annual cycle parameters as disaggregation kernels. Remote Sensing, 9, 23

Sobrino, J.A., Jiménez-Muñoz, J.C., \& Paolini, L. (2004). Land surface temperature retrieval from LANDSAT TM 5. Remote Sensing of Environment, 90, 434-440

Son, N., Chen, C., Chen, C., Chang, L., \& Minh, V. (2012). Monitoring agricultural drought in the Lower Mekong Basin using MODIS NDVI and land surface temperature data. International Journal of Applied Earth Observation and Geoinformation, 18, 417-427

Van Hove, L., Jacobs, C., Heusinkveld, B., Elbers, J., Van Driel, B., \& Holtslag, A. (2015). Temporal and spatial variability of 
urban heat island and thermal comfort within the Rotterdam agglomeration. Building and Environment, 83, 91-103

Vázquez-Jiménez, R., Ramos-Bernal, R.N., Romero-Calcerrada, R., Arrogante-Funes, P., Tizapa, S.S., \& Novillo, C.J. (2017). Thresholding Algorithm Optimization for Change Detection to Satellite Imagery. Colorimetry and Image Processing: IntechOpen

Wang, T., Kou, X., Xiong, Y., Mou, P., Wu, J., \& Ge, J. (2010). Temporal and spatial patterns of NDVI and their relationship to precipitation in the Loess Plateau of China. International Journal of Remote Sensing, 31, 1943-1958

Weng, Q. (2009). Thermal infrared remote sensing for urban climate and environmental studies: Methods, applications, and trends. Isprs Journal of Photogrammetry and Remote Sensing, 64, 335-344

Weng, Q., Firozjaei, M.K., Kiavarz, M., Alavipanah, S.K., \& Hamzeh, S. (2019). Normalizing land surface temperature for environmental parameters in mountainous and urban areas of a cold semi-arid climate. Science of the Total Environment, 650, 515-529

Weng, Q., Firozjaei, M.K., Sedighi, A., Kiavarz, M., \& Alavipanah, S.K. (2018). Statistical analysis of surface urban heat island intensity variations: A case study of Babol city, Iran. GIScience \& remote sensing, 1-29

Weng, Q., Lu, D., \& Schubring, J. (2004). Estimation of land surface temperature-vegetation abundance relationship for urban heat island studies. Remote Sensing of Environment, 89, 467-483 Xiao, H., \& Weng, Q. (2007). The impact of land use and land cover changes on land surface temperature in a karst area of China. Journal of environmental management, 85, 245-257

Xie, S.-P., Deser, C., Vecchi, G.A., Ma, J., Teng, H., \& Wittenberg, A.T. (2010). Global warming pattern formation: Sea surface temperature and rainfall. Journal of climate, 23, 966-986 Xunqiang, M., Chen, C., Fuqun, Z., \& Hongyuan, L. (2011). Study on temporal and spatial variation of the urban heat island based on Landsat TM/ETM+ in central city and Binhai New Area of Tianjin. In, Multimedia Technology (ICMT), 2011 International Conference on (pp. 4616-4622): IEEE

Yang, Y., Cao, C., Pan, X., Li, X., \& Zhu, X. (2017). Downscaling land surface temperature in an arid area by using multiple remote sensing indices with random forest regression. Remote Sensing, 9, 789

Zhan, W., Chen, Y., Zhou, J., Wang, J., Liu, W., Voogt, J., Zhu, X., Quan, J., \& Li, J. (2013). Disaggregation of remotely sensed land surface temperature: Literature survey, taxonomy, issues, and caveats. Remote Sensing of Environment, 131, 119-139

Zhao, W., Duan, S.-B., Li, A., \& Yin, G. (2019). A practical method for reducing terrain effect on land surface temperature using random forest regression. Remote Sensing of Environment, $221,635-649$ 